\title{
Effects of Oil Palm Shell Coarse Aggregate Species on High Strength Lightweight Concrete
}

\author{
Ming Kun Yew, ${ }^{1}$ Hilmi Bin Mahmud, ${ }^{1}$ Bee Chin Ang, ${ }^{2}$ and Ming Chian Yew ${ }^{1}$ \\ ${ }^{1}$ Department of Civil Engineering, Faculty of Engineering, University of Malaya, 50603 Kuala Lumpur, Malaysia \\ ${ }^{2}$ Center of Advanced Materials, Department of Mechanical Engineering, Faculty of Engineering, University of Malaya, \\ 50603 Kuala Lumpur, Malaysia
}

Correspondence should be addressed to Ming Kun Yew; davidyew1983@gmail.com

Received 6 March 2014; Revised 22 April 2014; Accepted 22 April 2014; Published 29 May 2014

Academic Editor: İlker Bekir Topçu

Copyright (C) 2014 Ming Kun Yew et al. This is an open access article distributed under the Creative Commons Attribution License, which permits unrestricted use, distribution, and reproduction in any medium, provided the original work is properly cited.

\begin{abstract}
The objective of this study was to investigate the effects of different species of oil palm shell (OPS) coarse aggregates on the properties of high strength lightweight concrete (HSLWC). Original and crushed OPS coarse aggregates of different species and age categories were investigated in this study. The research focused on two OPS species (dura and tenera), in which the coarse aggregates were taken from oil palm trees of the following age categories (3-5, 6-9, and 10-15 years old). The results showed that the workability and dry density of the oil palm shell concrete (OPSC) increase with an increase in age category of OPS species. The compressive strength of specimen CD3 increases significantly compared to specimen CT3 by $21.8 \%$. The maximum achievable 28 -day and 90 day compressive strength is 54 and $56 \mathrm{MPa}$, respectively, which is within the range for 10-15-year-old crushed dura OPS. The water absorption was determined to be within the range for good concrete for the different species of OPSC. In addition, the ultrasonic pulse velocity (UPV) results showed that the OPS HSLWC attain good condition at the age of 3 days.
\end{abstract}

\section{Introduction}

The environmental impact of oil palm cultivation is a highly controversial topic. Oil palm shells (OPS) are agricultural solid end products of oil palm manufacturing processes. Palm trees grow in regions where the temperature is hot with copious rainfall such as Malaysia, Indonesia, and Nigeria. In Malaysia, oil palm fruits can be classified as dura, tenera, and pisifera. dura is a homozygous dominant with thick shells while pisifera is a homozygous recessive without shells. A ring of fibres called "mesocarp" surrounds the kernel. dura is cross-pollinated with pisifera to produce heterozygous tenera with an intermediate shell thickness surrounded by a ring of fibres in the mesocarp. It has been shown that high strength lightweight aggregate concrete (HSLWAC) has a compressive strength of typically between 34 and $69 \mathrm{MPa}$ through the incorporation of various pozzolans and water reducers. HSLWAC has a water to cement ratio less than 0.45 and an air-dry density less than $2000 \mathrm{~kg} / \mathrm{m}^{3}$ [1]. The utilization of OPS as lightweight aggregate (LWA) in the production of lightweight aggregate concrete (LWAC) has been a topic of research since the early 1984 in Malaysia by Abdullah [2]. Palm oil production is a significant industry in the Malaysian economy, as Malaysia is the world's second largest producer of the commodity in 2012 [3]. The need for vegetable oils is constantly increasing and an increase in the cultivation of palm oil is forecasted in the near future. Malaysia produces 18.79 million tonnes of crude palm oil on roughly 5 million hectares of land $[4,5]$. Even though Indonesia produces more palm oil, Malaysia is the world's largest exporter of palm oil, in which 18 million tonnes of palm oil products were exported in 2011. China, Pakistan, the European Union, India, and the United States of America are the primary importers of Malaysian palm oil products [6]. Approximately $80 \%$ of the volume from fresh fruit bunch processing is removed as waste [7]. A prevailing problem in the processing of palm oil is the large amounts of byproducts produced such as empty fruit bunches (EFB), palm kernel shells (PKS), oil palm shells (OPS), and palm oil mill effluent (POME). These by-products are one of the main 
TABLE 1: Chemical composition and physical properties of OPC.

\begin{tabular}{|c|c|c|c|c|c|c|c|c|}
\hline \multicolumn{6}{|c|}{ Chemical composition (\%) } & \multicolumn{3}{|c|}{ Physical properties } \\
\hline $\mathrm{SiO}_{2}$ & $\mathrm{Fe}_{2} \mathrm{O}_{3}$ & $\mathrm{CaO}$ & $\mathrm{MgO}$ & $\mathrm{Al}_{2} \mathrm{O}_{3}$ & $\mathrm{SO}_{3}$ & LOI & Specific gravity & Blain specific surface area $\left(\mathrm{cm}^{2} / \mathrm{g}\right)$ \\
\hline 21.28 & 3.36 & 64.64 & 2.06 & 5.6 & 2.14 & 0.64 & 3.14 & 3510 \\
\hline
\end{tabular}

contributors to the nation's pollution problem. OPS are one of the wastes produced during palm oil processing. Recently, a large amount of OPS waste materials are stockpiled and dumped, which causes storage problems within the vicinity of factories as large quantities of these wastes are produced every day [8]. In Malaysia, it is estimated that over 4.6 million tonnes of OPS is produced annually as waste [9]. The density of the shells is within the range of a majority of commonplace lightweight aggregates [10] and the specific gravity of the shells ranges between 1.14 and 1.37. A number of studies over the last two decades showed that OPS can be employed as LWA in order to produce structural LWAC, with a reduction in density of 20-25\% compared to normal weight concrete [11]. These types of LWA will not only provide significant savings in the overall construction costs, but also address concomitant environmental problems by reducing solid waste. A cost analysis in Nigeria [12] revealed that a cost reduction of $42 \%$ is possible for concrete made from OPS. Several studies showed that although the engineering properties of OPSC are generally satisfactory [13-16], there is still reluctance in implementing OPSC compared with other types of LWAC. The reason for this was given by Okafor [10], who concluded that OPS are incapable of producing concrete with a compressive strength above $30 \mathrm{MPa}$. However, recent studies have shown that high strength LWAC can indeed be produced [17-19].

Most current studies on OPSLWC focused on the investigation of their engineering properties and no information is available regarding the influence of different species and age categories of OPS coarse aggregates on the properties of lightweight concrete. Shafigh et al. [17] reported that the difference between old and fresh OPS is in the fibre content of the surface. The percentage of fibres for old OPS grains is less than $5 \%$ compared with fresh OPS grains which usually contain more than $50 \%$ fibres. The percentage of fibres increases the demand for water and diminishes the contact area between the mortar and OPS surface, which results in a weak interfacial transition zone. This in turn, affects the bonding strength between the OPS and mortar phase. A new method for producing high strength oil palm shell lightweight concrete was implemented by Shafigh et al. [18]. The flakiness of large-sized OPS aggregates is reduced significantly by crushing these aggregates which improve the performance of coarse aggregates and increases compressive strength. However, it has been shown that the different species and age categories of OPS coarse aggregates have the most significant impact on the production of high strength OPS lightweight concrete. Considerable research has been devoted on the application of various species and age categories of OPS aggregates to enhance the properties of OPS HSLWC. The methods proposed based on the results of such studies are commonly termed "OPS selection methods."
OPS selection method is considered to be an environmentalfriendly alternative compared to chemically impregnated OPS materials [20] in enhancing the properties of HSLWC. Hence, this study was motivated based on the foundation that different species of OPS aggregates possess better characteristics which will offer interesting opportunities in the production of OPS HSLWC and forms the objective of this study.

\section{Materials and Methods}

\subsection{Materials}

2.1.1. Cement. The cement used in this study was ASTM type I ordinary portland cement (OPC) [21] with a specific gravity of $3.14 \mathrm{~g} / \mathrm{cm}^{3}$ and a Blaine's specific surface area of $3510 \mathrm{~cm}^{2} / \mathrm{g}$. The cement content was kept constant at $550 \mathrm{~kg} / \mathrm{m}^{3}$. Silica fume (SF) having $5 \%$ cement by weight and a specific gravity of $2.10 \mathrm{~g} / \mathrm{cm}^{3}$ was used as the supplementary cementitious material. To enhance the mechanical properties of the concrete, densified SF was added as additional mineral admixture. The silica fume used for this research investigation was procured from Scancem Materials Sdn. Bhd. The chemical composition and physical properties of OPC are presented in Table 1 .

2.1.2. Water and Superplasticizer (SP). Potable water with a $\mathrm{pH}$ value of 6 was used for all mixes. Polycarboxylic ether (PCE) supplied by BASF was used as the superplasticizer (SP) in this study complies with the ASTM: C494/C494M-13 standard. The SP was mixed at a constant amount of $1.0 \%$ of the cement weight in order to facilitate workability. A waterto-binder ratio of 0.3 was used for all mixes.

2.1.3. Fine and Coarse Aggregates. Local mining sand was used as the fine aggregate, having a specific gravity, fineness modulus, water absorption, and maximum grain size of $2.68 \mathrm{~g} / \mathrm{m}^{3}, 2.72,0.97 \%$, and $4.75 \mathrm{~mm}$, respectively. The fine aggregate content was kept constant at $860 \mathrm{~kg} / \mathrm{m}^{3}$ for all mixes.

OPS were used as the coarse aggregate in this study. Different species of dura, tenera and pisifera OPS are shown in Figure 1, while different age categories of dura and tenera used are shown in Figures 2, 3, and 4. The OPS aggregates used in this study are classified as "immature" from 3 to 5 years of age, "young mature" from 6 to 9 years of age, and "young prime" from 10 to 15 years of age. The OPS were collected from a local crude palm oil factory in both original and crushed conditions, as shown in Figures 5 and 6, respectively. It can be seen that the original OPS have concave and convex shapes with a smooth surface on the outer convex side, 


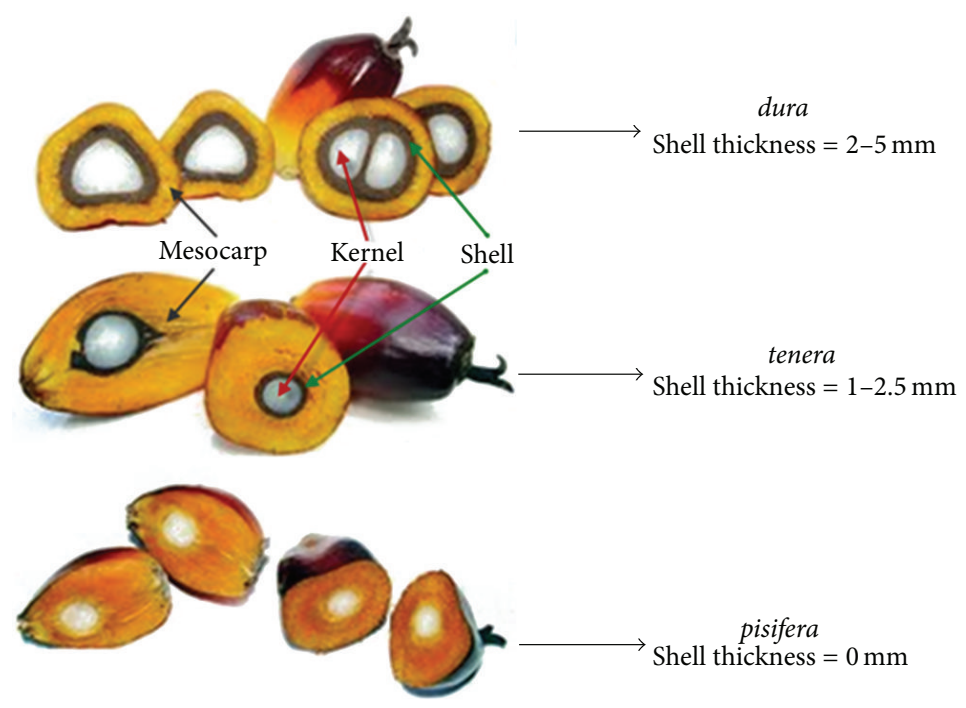

FIGURE 1: Species of OPS coarse aggregates.

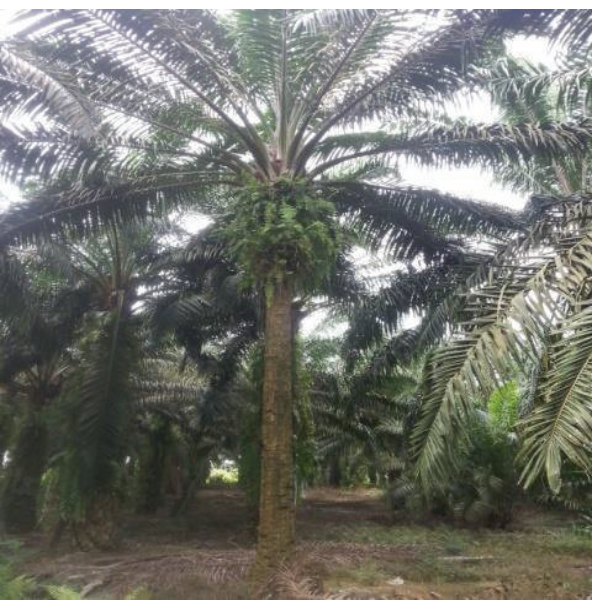

(a)

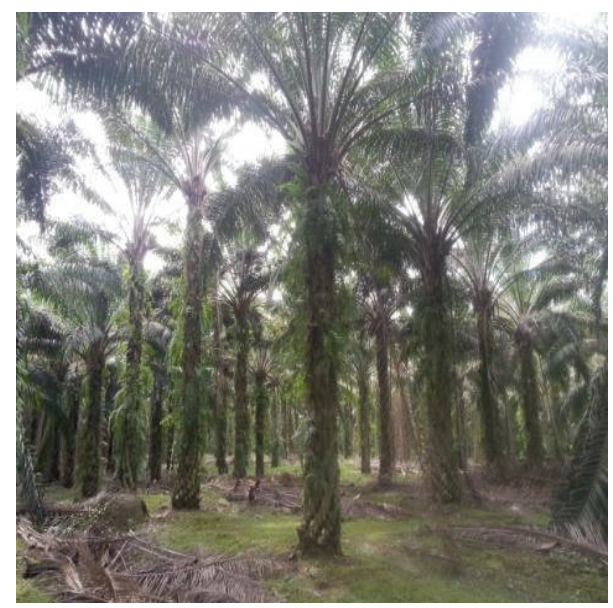

(b)

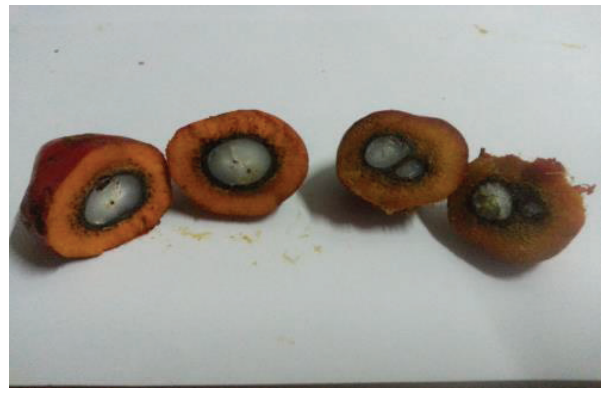

(c)

FIGURE 2: dura (a) and tenera (b) OPS aggregates taken from 10-15-year-old oil palm trees.

whereas the crushed OPS have more spiky edges compared to the original OPS. The OPS aggregates were subsequently air dried in the laboratory to attain an approximately saturated surface dry condition. The aggregates were sieved using a 12.5 and $9.5 \mathrm{~mm}$ sieve in order to investigate the effect of OPS aggregate size on the compressive strength of the concrete. This yields OPS aggregates with a different maximum size. A comparison between the physical properties of OPS aggregates and crushed granite is presented in Table 2, while the grading of OPS aggregates is presented in Table 3. The OPS content was kept constant at $380 \mathrm{~kg} / \mathrm{m}^{3}$ for all mixes. 


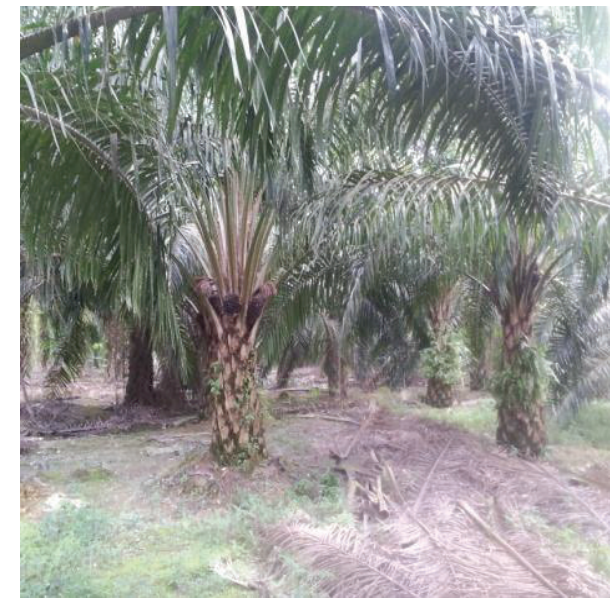

(a)

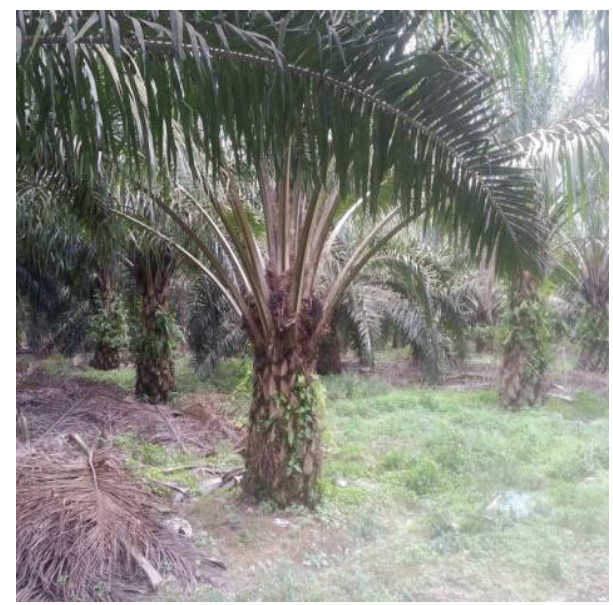

(b)

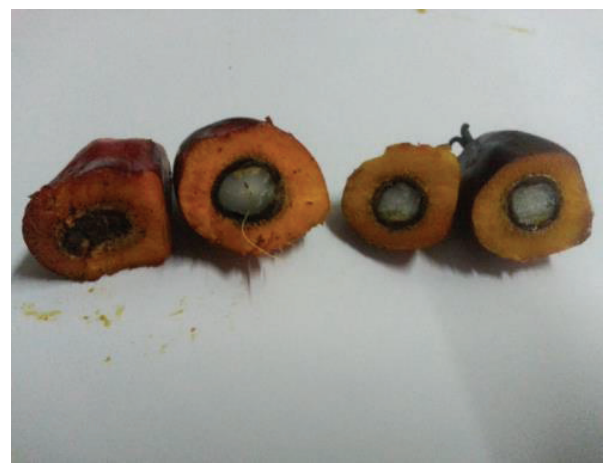

(c)

FIGURE 3: dura (a) and tenera (b) OPS aggregates taken from 6-9-year-old oil palm trees.

TABLE 2: Comparison between the physical properties of OPS aggregates and crushed granite [22].

\begin{tabular}{|c|c|c|c|c|c|}
\hline Physical property & Original dura OPS & Original tenera OPS & Crushed dura OPS & Crushed tenera OPS & Crushed granite [23] \\
\hline Maximum size (mm) & 12.5 & 12.5 & 9.5 & 9.5 & - \\
\hline $\begin{array}{l}\text { Specific gravity } \\
\text { (saturated surface dry) }\end{array}$ & $1.28-1.33$ & $1.15-1.22$ & $1.30-1.37$ & $1.19-1.27$ & 2.61 \\
\hline Compacted bulk density $\left(\mathrm{kg} / \mathrm{m}^{3}\right)$ & $612-670$ & $596-617$ & $620-684$ & $608-624$ & 1470 \\
\hline Water absorption $(24 \mathrm{~h})(\%)$ & 24.8 & 18.9 & 19.6 & 17.9 & 0.76 \\
\hline Aggregate impact value (\%) & 2.10 & 2.03 & 2.60 & 2.35 & 17.29 \\
\hline
\end{tabular}

TABLE 3: Grading of OPS aggregates.

\begin{tabular}{|c|c|c|c|c|}
\hline \multirow{2}{*}{$\begin{array}{l}\text { Sieve size } \\
(\mathrm{mm})\end{array}$} & \multicolumn{4}{|c|}{ Cumulative $\%$ by weight passing sieve size } \\
\hline & Original dura OPS (12.5 mm) & Original tenera OPS (12.5 mm) & Crushed dura OPS (9.5 mm) & Crushed tenera OPS $(9.5 \mathrm{~mm})$ \\
\hline 20 & 100 & 100 & 100 & 100 \\
\hline 12.5 & 100 & 100 & 100 & 100 \\
\hline 9.5 & 82.28 & 83.22 & 100 & 100 \\
\hline 8 & 58.26 & 59.27 & 93.52 & 94.62 \\
\hline 4.75 & 23.45 & 22.78 & 24.13 & 23.65 \\
\hline 2.36 & 4.41 & 4.28 & 5.39 & 5.34 \\
\hline
\end{tabular}




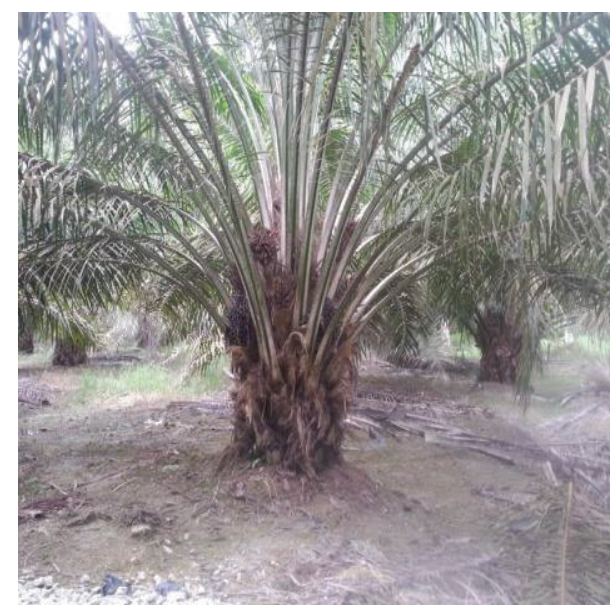

(a)

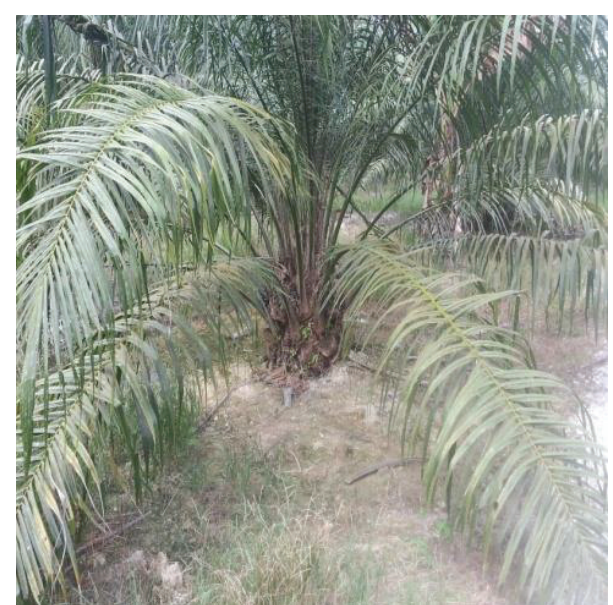

(b)

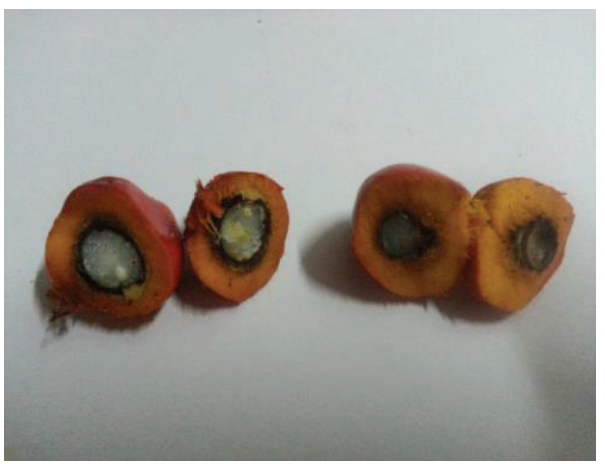

(c)

FIGURE 4: dura (a) and tenera (b) OPS aggregates taken from 3-5-year-old oil palm trees.

TABLE 4: Different species of OPS and the age categories of original and crushed OPS mixes.

\begin{tabular}{lccc}
\hline Number & Mix code & OPS species & Age categories (years old) \\
\hline Original OPS & & & \\
1 & OD1 & dura & 3 to 5 \\
2 & OD2 & dura & 6 to 9 \\
3 & OD3 & dura & 10 to 15 \\
4 & OT1 & tenera & 3 to 5 \\
5 & OT2 & tenera & 6 to 9 \\
6 & OT3 & tenera & 10 to 15 \\
Crushed OPS & & & \\
7 & CD1 & dura & 3 to 5 \\
8 & CD2 & dura & 6 to 9 \\
9 & CD3 & dura & 10 to 15 \\
10 & CT1 & tenera & 3 to 5 \\
11 & CT2 & tenera & 6 to 9 \\
12 & CT3 & tenera & 10 to 15 \\
\hline
\end{tabular}

2.2. Mix Proportions. A total of 12 mixes were prepared in this study and the mix proportions are presented in Table 4 . The dosage of water and SP was kept constant for all mixes.
2.3. Testing Methods and Curing Regimes. The procedure used to prepare OPSC is detailed as follows. Firstly, the sand and OPS were poured into a concrete mixer and dry-mixed for $1 \mathrm{~min}$. Secondly, the cement was spread and dry-mixed for $1 \mathrm{~min}$. Water and superplasticizer were then added and mixed for $5 \mathrm{~min}$. Slump test was performed on the mixture prior to sample casting. The fresh concrete mix was placed into $100 \mathrm{~mm}$ cube steel oiled moulds and a poker vibrator was used to eliminate air bubbles in the mixture. The specimens were demoulded approximately 24 hours after casting and were cured in water at $25 \pm 2^{\circ} \mathrm{C}$ until the age of testing. The compressive strength was determined at $1,3,7,14,28$, 56 , and 90 days using a compression testing machine with a capacity of $3000 \mathrm{kN}$ and equipped with a rate of loading controller, in accordance to the British Standard (BS) 1881. Three concrete cubes were cast for each mixture in order to determine the average value at a particular age. In order to determine the water absorption of all mixes at the age of 28 days, the specimens were dried in an oven at $100 \pm 5^{\circ} \mathrm{C}$ until a constant mass was reached and then fully immersed in water at $22 \pm 2^{\circ} \mathrm{C}$ for $72 \mathrm{~h}$. This test is similar to the test conducted by Razak et al. [24], Teo et al. [25], and Shafigh et al. [17].

The specimens were cured under seven types of curing condition to determine the effect of curing environment on 


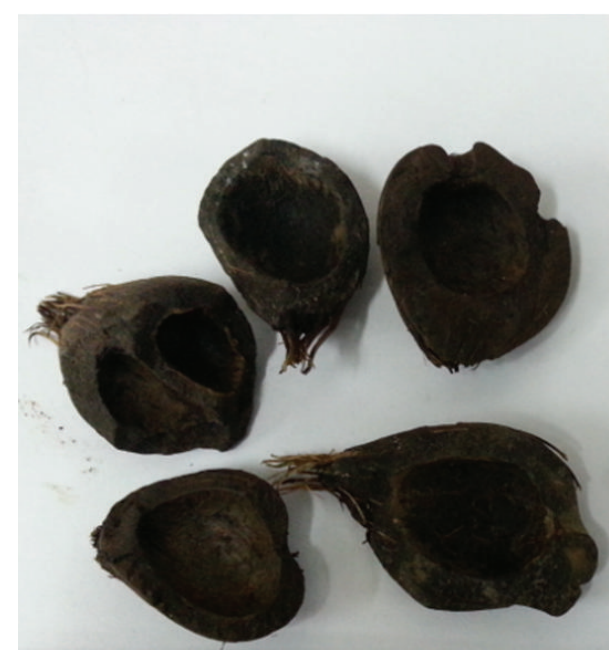

(a)

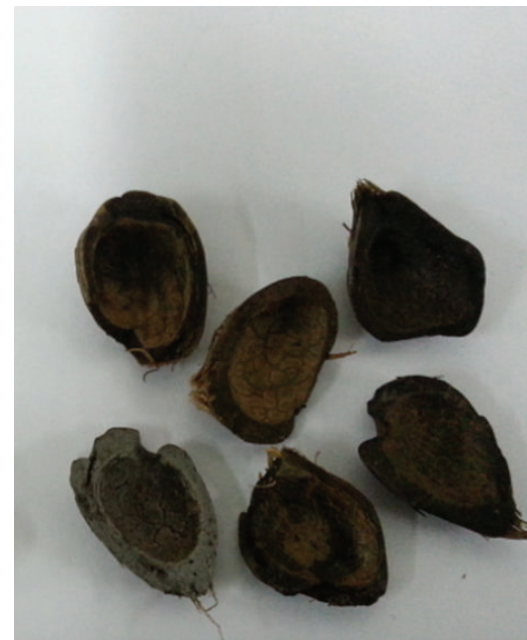

(b)

FIGURE 5: Original dura (a) and tenera (b) OPS coarse aggregates.

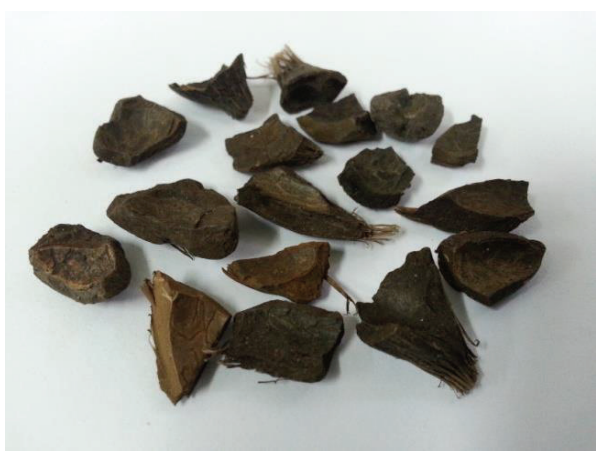

(a)

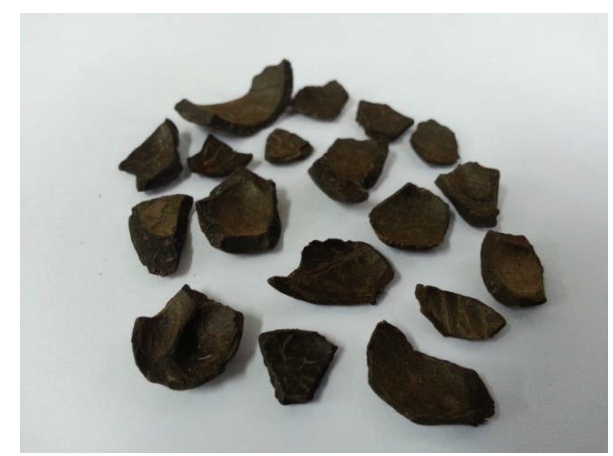

(b)

FIgURE 6: Crushed dura (a) and tenera (b) OPS coarse aggregates.

the 28-day compressive strength of high strength OPSC. A brief description of each curing condition is given as follows:

(i) WC: the specimens were immersed in water at $22 \pm$ $2^{\circ} \mathrm{C}$ after demoulding until the age of testing;

(ii) $14 \mathrm{~W}$ : the specimens were cured in water for 13 days after demoulding and then air-cured in laboratory environment with a relative humidity of $60 \pm 10 \%$ and temperature of $29 \pm 3^{\circ} \mathrm{C}$;

(iii) $2 \mathrm{~T} 14 \mathrm{D}$ : the specimens were watered twice per day (once in the morning and afternoon) for 13 days after demoulding and then air-cured in laboratory environment;

(iv) 7W: the specimens were cured in water for 6 days after demoulding and then air-cured in laboratory environment with a relative humidity of $60 \pm 10 \%$ and temperature of $29 \pm 3^{\circ} \mathrm{C}$;

(v) 2T7D: the specimens were watered twice per day (once in the morning and afternoon) for 6 days after demoulding and then air-cured in laboratory environment; (vi) 2T3D: the specimens were watered twice per day (once in the morning and afternoon) for 2 days after demoulding and then air-cured in laboratory environment;

(vii) AC: the specimens were stored in laboratory environment after demoulding.

\section{Results and Discussion}

3.1. Properties of Fresh Concrete (Workability). Slump test was carried out to determine the consistency of fresh concrete. The effect of original and crushed OPS species and age category on the slump values of fresh concrete specimens is summarized in Figure 7 . The specimens were tested immediately after mixing as well as at 10,20, and $30 \mathrm{~min}$ to determine the slump loss of the mixtures. It can be observed that the concrete mixes achieved maximum slump at $20 \mathrm{~min}$, which indicates that a longer period is required to enable the SP to react with fresh concrete in order to achieve good workability for OPSC. It was found that the workability of fresh OPSC 


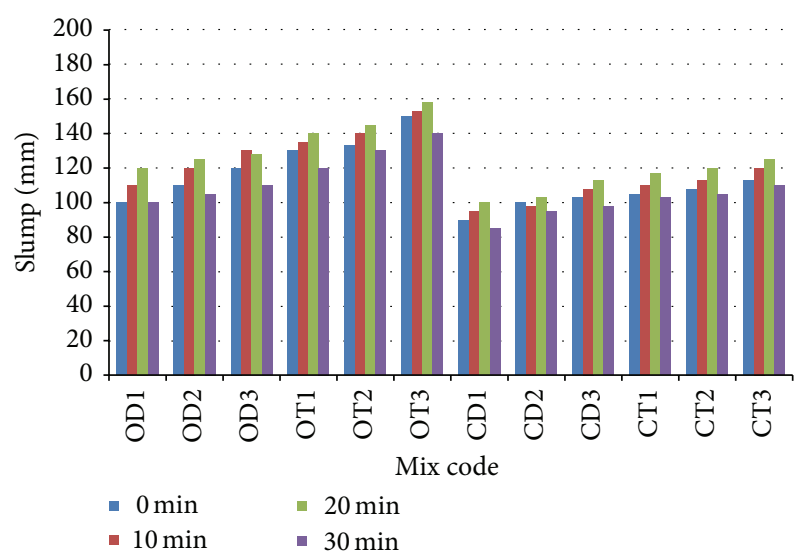

FIGURE 7: Effect of OPS species (original and crushed) and age categories on workability.

improves with an increase in age category and varies from crushed OPS to original OPS aggregates.

In general, all mixes exhibit "good" to "high workability" within a range of $90-150 \mathrm{~mm}$. It can be seen that all the concretes mixes had a maximum slump at $10 \mathrm{~min}$ or $20 \mathrm{~min}$. This phenomenon shows that to achieve better workability for OPSC it needs more time for mixing. The OT3 mix had the highest slump value of $158 \mathrm{~mm}$ at $20 \mathrm{~min}$. Segregation and bleeding were not observed in these mixes, as it is possible that the highest age category for the original tenera OPS aggregates reduces water absorption, which increases the workability and flow of the concrete. The CD1 mix had the lowest slump value among the mixes, because the maximum size of the crushed OPS aggregates of the mix was reduced from 12.5 to $9.5 \mathrm{~mm}$. This affects the workability of the mix because it contains variety of irregular shapes of the OPS which prevented full compaction from being achieved, as well as the higher water absorption of OPS. Furthermore, it can be observed that, from the time of leaving the mixer, all the concrete mix exhibited slump loss at $30 \mathrm{~min}$. A previous study reported that the concrete slump increases slightly when the maximum size of the OPS aggregates increases from 9.5 to $12.5 \mathrm{~mm}$ [17]. The strength of the interfacial transition zone tends to increase by improving the workability and compatibility of the mixture, which increases the strength of the concrete.

3.2. Density. Three types of density (demoulded density, 28day air-dry density, and oven-dry density) were measured for all mixes. Structural lightweight concrete (LWC) is typically defined as concrete with an oven-dry density less than $2000 \mathrm{~kg} / \mathrm{m}^{3}$ [23]. It was found that the density of all the mixes is within the range of structural LWC for all mixes, as shown in Figure 8. The 28-day air-dry density and oven-dry density for the original and crushed OPS mixes range between 1871$1876 \mathrm{~kg} / \mathrm{m}^{3}$ and $1983-1986 \mathrm{~kg} / \mathrm{m}^{3}$, respectively. Assuming that the density for normal weight concrete (NWC) is $2350 \mathrm{~kg} / \mathrm{m}^{3}$, the 28-day air-dry density and oven-dry density for all mixes

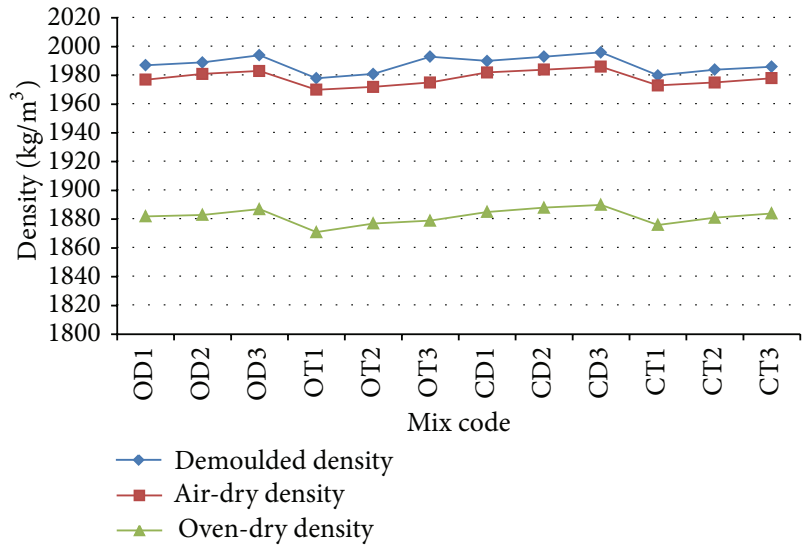

Figure 8: Variations of demoulded density, air-dry density, and oven-dry density for concrete mixes made from different species of OPS (original and crushed) and age categories.

are approximately $20 \%$ and $16 \%$ lower than that of ordinary concrete, respectively.

An increase in age category for the original dura OPS species from 3-5 years old to 6-9 and 10-15 years old slightly increases the demoulded density, air-dry density, and ovendry density by $0.2 \%$ and $0.3 \%$ at $1 \mathrm{~d}, 0.1 \%$ and $0.2 \%$ at $3 \mathrm{~d}$, or $7 \mathrm{~d}$ and $0.2 \%$ and $0.3 \%$ at $28 \mathrm{~d}$, respectively. A similar trend can be observed for other OPSC mixes, as shown in Figure 8.

\subsection{Compressive Strength}

3.3.1. Continuous Moist Curing. The results of the compressive strength for all concrete mixes subjected to moist curing up to 90 days are presented in Table 5. It was found that the CD3 concrete mix had the highest compressive strength, with a value of 54 and $56 \mathrm{MPa}$ at $28 \mathrm{~d}$ and $90 \mathrm{~d}$, respectively. The compressive strength increases with an increase in age category for different species of original and crushed OPS at all ages. The mixes of CD1 to CD3 increase the compressive strength by $4.8 \%$ and $8.0 \%$ at $1 \mathrm{~d}, 7.5 \%$ and $11.3 \%$ at $3 \mathrm{~d}, 5.6 \%$ and $11.3 \%$ at $7 \mathrm{~d}, 5.0 \%$ and $9.9 \%$ at $14 \mathrm{~d}, 5.1 \%$ and $6.5 \%$ at $28 \mathrm{~d}$, and $1.6 \%$ and $5.9 \%$ at $90 \mathrm{~d}$, respectively. This observation may be attributed to the thicker and larger (and hence harder and stronger) OPS aggregates with respect to the age category of the oil palm trees. The compressive strength increases by $9.0 \%, 11.6 \%$, and $16.5 \%$ from OD1-OD3 to CD1-CD3 at $28 \mathrm{~d}$, when the maximum size of OPS aggregates changes from original $(12.5 \mathrm{~mm})$ to crushed $(9.5 \mathrm{~mm})$. From the results, it is evident that the flakiness index of the aggregates reduces significantly and a higher stiffness is attained when the OPS aggregates were crushed to smaller sizes, particularly for the CD3 mix. A previous study reported that the transition zone will weaken significantly when large aggregates are used, due to internal bleeding and development of microcracks, which results in lower compressive strength [26]. Although the surface texture of the concave and convex faces of dura and tenera OPS is fairly smooth, the broken edges of dura OPS are rough and spiky compared to tenera OPS, which 
TABLE 5: Development of compressive strength of lightweight OPSC under continuous moist curing.

\begin{tabular}{|c|c|c|c|c|c|c|c|}
\hline \multirow{2}{*}{ Mix code } & \multicolumn{7}{|c|}{ Compressive strength $(\mathrm{MPa})^{\mathrm{a}}$} \\
\hline & $1 \mathrm{~d}$ & $3 \mathrm{~d}$ & $7 \mathrm{~d}$ & $14 \mathrm{~d}$ & $28 \mathrm{~d}$ & $56 \mathrm{~d}$ & $90 \mathrm{~d}$ \\
\hline OD1 & $29.2(65.32)$ & $34.9(77.92)$ & $40.2(87.21)$ & $42.5(94.86)$ & 44.8 & $46.1(103.06)$ & $48.0(107.24)$ \\
\hline OD2 & $29.5(64.29)$ & $35.0(76.30)$ & $40.9(87.63)$ & $43.1(93.97)$ & 45.9 & 46.7 (101.63) & $48.1(104.66)$ \\
\hline OD3 & $29.8(63.73)$ & $36.0(76.80)$ & $41.0(86.27)$ & $44.3(94.57)$ & 46.9 & $47.6(101.58)$ & $48.4(103.40)$ \\
\hline OT1 & $27.7(68.49)$ & $31.9(78.99)$ & $35.2(84.21)$ & $37.3(92.32)$ & 40.4 & $41.9(103.67)$ & $43.0(106.59)$ \\
\hline OT2 & $28.0(68.92)$ & $32.2(79.22)$ & $36.6(86.83)$ & $38.7(95.11)$ & 40.7 & $42.1(103.59)$ & $44.8(110.08)$ \\
\hline OT3 & $28.6(69.24)$ & $32.9(79.64)$ & $37.1(86.39)$ & $39.1(94.76)$ & 41.3 & $43.0(104.17)$ & $45.2(109.65)$ \\
\hline CD1 & $31.3(64.09)$ & $38.4(78.65)$ & $42.1(81.66)$ & $44.8(91.84)$ & 48.8 & $51.6(105.78)$ & $52.0(106.73)$ \\
\hline CD2 & $32.8(63.93)$ & $41.2(80.48)$ & $44.5(84.78)$ & 47.0 (91.78) & 51.2 & $52.4(102.36)$ & $52.9(103.24)$ \\
\hline CD3 & $35.4(64.82)$ & $45.9(84.12)$ & $49.5(88.74)$ & $51.7(94.70)$ & 54.4 & $55.8(102.25)$ & $56.0(102.69)$ \\
\hline CT1 & $28.7(68.29)$ & $33.2(79.18)$ & 37.9 (87.99) & $39.6(94.28)$ & 42.0 & $43.0(102.53)$ & 45.8 (109.08) \\
\hline CT2 & $28.8(68.05)$ & $33.5(79.20)$ & $38.6(87.87)$ & $40.2(94.92)$ & 42.4 & 43.9 (103.73) & $46.0(108.64)$ \\
\hline CT3 & $28.9(67.69)$ & $33.7(78.84)$ & $38.8(87.06)$ & $40.5(95.00)$ & 42.7 & $44.5(104.31)$ & $46.9(109.82)$ \\
\hline
\end{tabular}

${ }^{a}$ The data in parentheses are percentage of $28 \mathrm{~d}$ compressive strength.

strengthens the physical bond between the aggregates and hydrated cement paste.

From Table 5, it can be observed that all mixes achieved high early strength at 7 days of age. The mixes reached $64-69 \%, 32-46 \%$, and $82-89 \%$ of the 28 -day compressive strength at $1 \mathrm{~d}, 3 \mathrm{~d}$, and $7 \mathrm{~d}$, respectively. The high early strength may be attributed to the addition of silica fume since the pozzolanic reaction and microfiller effects of the silica fume contribute to the early strength of OPSC. The addition of silica fume improves bonding within the OPSC and helps reduce permeability. The silica fume reacts with the weak leachable calcium hydroxide $(\mathrm{CaOH})$ liberated from hydration of the cement to form strong dense calcium silicate hydrate $(\mathrm{C}-\mathrm{S}-\mathrm{H})$. As a microfiller, the extreme fineness of the silica fume allows it to fill the microscopic voids between the cement particles. This greatly reduces permeability and improves the OPS aggregate-cement paste in the interfacial zone, and, consequently minimizes the induction of microcracks compared to conventional concrete.

An additional benefit of OPS aggregate selection can be observed from the compressive strength of the CD3 mix, whereby the cement content of this mix is $550 \mathrm{~kg} / \mathrm{m}^{3}$, which gives a 28 -day compressive strength of $54 \mathrm{MPa}$. Alengaram et al. [27] produced grade 30 OPSC, in which cement having a density range of $504-564 \mathrm{~kg} / \mathrm{m}^{3}$ was mixed with $5 \%$ fly ash and $10 \%$ silica fume as additional cementitious materials. The total cementitious material of their study was within the range of $585-654 \mathrm{~kg} / \mathrm{m}^{3}$. It is evident that the cement content of the CD3 mix falls within the range used by Alengaram et al. [27] and that the CD3 mix contains 5\% supplementary cementitious materials that are lower compared to their study. This indicates that the methodology adopted in this study yields a compressive strength that is significantly higher for OPSC than that obtained by Alengaram et al. [27].

3.4. Effect of Curing Condition on the 28-Day Compressive Strength. Curing can be defined as a procedure used to ensure the hydration of Portland cement in newly placed concrete. In general, curing implies the control of moisture loss and effects of temperature in concrete during its early stages so that the desired properties may develop [28]. As a general rule, at least 14 days of good curing is necessary for OPSC. Although a minimum period of 7 days of moist curing is generally recommended for concrete containing normal Portland cement or a mineral admixture, a longer curing period is desirable to ensure higher strength contribution from pozzolanic reactions [29]. The 28-day compressive strength of specimens subjected to seven curing conditions is shown in Figure 9. It can be observed that all concrete mixes experienced a strength loss in air curing or early curing regimes compared to those that were water-cured continuously, regardless of mix proportions. The compressive strength loss for the 28-day specimens under air curing (AC) is within the range of $12.7-17.9 \%$, while the values are within $5.3-16.0 \%$ under partial early curing (2T3D, 2T7D, and $2 \mathrm{~T} 14 \mathrm{D})$. The compressive strength loss for the 28-day specimens is within $8.9-13.6 \%$ and $4.9-8.2 \%$ under early curing of $7 \mathrm{~W}$ and $14 \mathrm{~W}$, respectively. The average 28 -day compressive strength under AC, 2T3D, 2T7D, 7W, and $14 \mathrm{~W}$ curing conditions is approximately $84 \%, 87 \%, 88 \%, 89 \%$, $93 \%$, and $94 \%$ of that for concrete under full water curing condition, respectively. The high early strength of the OPSC may also be contributed by the highly reactive and microfiller effects of the silica fume.

The relationship between the early-age strength and 28day strength for different species of OPSC and age categories is presented in Figure 10. It is observed that there is an acceptable linear relationship between the early age and 28-day strength for mixes with different OPS species and age categories for crushed and original OPS aggregates, with a high correlation coefficient. Such a high correlation coefficient could also be observed for OPSC made with crushed OPS aggregates [24]. Furthermore, high correlation coefficients were also observed for OPSC made from OPS aggregates subject to heat treatment [19]. 


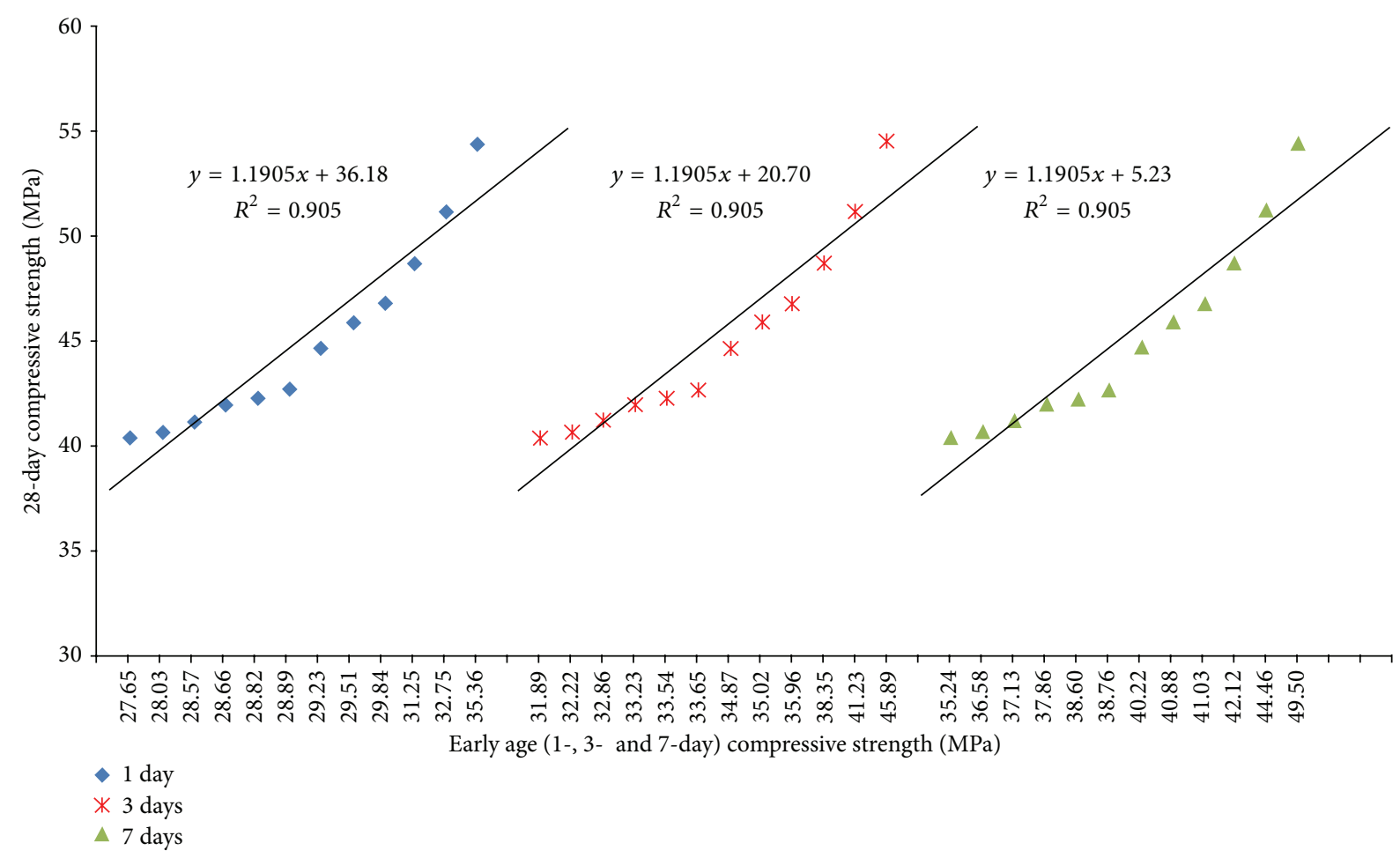

FIGURE 9: Effect of curing conditions on the 28-day compressive strength of concrete mixes.

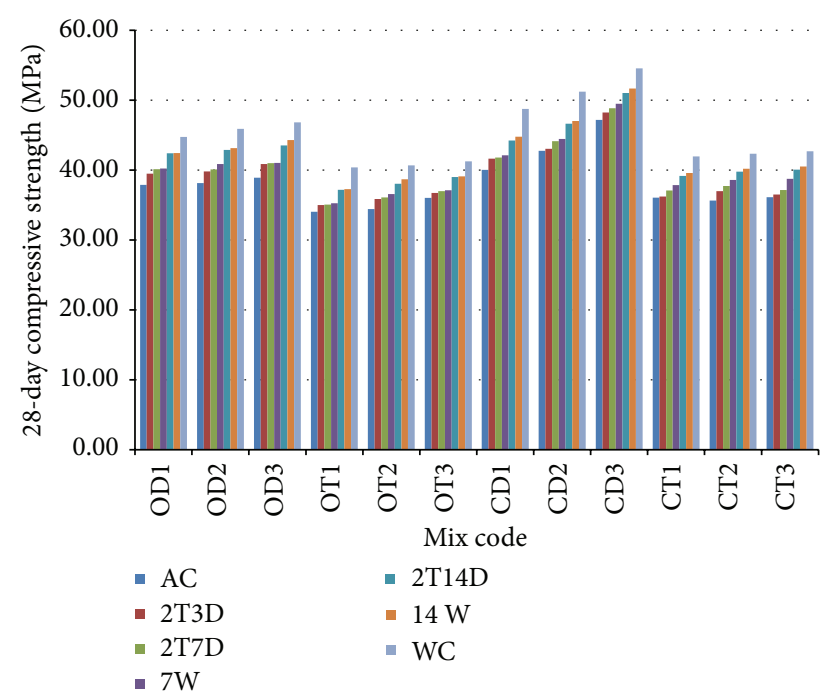

FigURE 10: Relationship between early age (1-, 3-, and 7-day) and 28day compressive strength for mixes made from different OPS species (original and crushed) and age categories.

3.5. Water Absorption. The water absorption for all mixes is given in Figure 11. In this study, it was observed that the lowest water absorption value is $3.04 \%$ while the highest water absorption value is $6.30 \%$ for high strength OPSC. Moreover, it can be seen that the water absorption for crushed OPS species is higher with an increase in age category compared to the original OPS species. This may be due to the broken

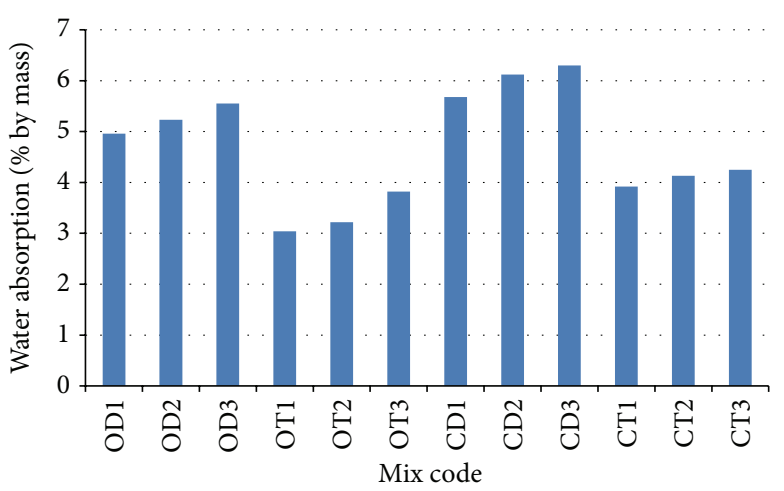

FIGURE 11: Water absorption of various concrete mixes made from different OPS species and age categories.

edges of the crushed OPS species that are rough and spiky, and therefore the crushed aggregates tend to absorb water. In contrast, the surface texture of the concave and convex faces of the original OPS species is fairly smooth, which may reduce water absorption. It has been stated that most good concrete have water absorption below $10 \%$ by weight [30]. Thus, it can be deduced that the water absorption value measured for the OPSC in this study falls within the range of good concrete. It has been reported that the water absorption for expanded polystyrene aggregate concrete [31] and pumice aggregate concrete [32] is within the range of 3-6\% and 14$22 \%$, respectively. 
TABLE 6: Ultrasonic pulse velocity (UPV) for concrete mixes made from different OPS species and age categories.

\begin{tabular}{|c|c|c|c|c|c|c|c|}
\hline \multirow{2}{*}{ Mix code } & \multicolumn{7}{|c|}{ UPV $(\mathrm{km} / \mathrm{s})$} \\
\hline & $1 \mathrm{~d}$ & $3 \mathrm{~d}$ & $7 \mathrm{~d}$ & $14 \mathrm{~d}$ & $28 \mathrm{~d}$ & $56 \mathrm{~d}$ & $90 \mathrm{~d}$ \\
\hline OD1 & 3.49 & 3.75 & 3.92 & 3.94 & 3.96 & 4.02 & 4.04 \\
\hline OD2 & 3.50 & 3.80 & 3.93 & 3.95 & 4.00 & 4.01 & 4.05 \\
\hline OD3 & 3.51 & 3.83 & 3.93 & 3.95 & 4.01 & 4.03 & 4.05 \\
\hline OT1 & 3.47 & 3.51 & 3.81 & 3.59 & 3.92 & 3.94 & 3.95 \\
\hline OT2 & 3.48 & 3.52 & 3.85 & 3.61 & 3.92 & 3.95 & 3.96 \\
\hline OT3 & 3.48 & 3.52 & 3.88 & 3.62 & 3.93 & 3.95 & 3.97 \\
\hline CD1 & 3.52 & 3.92 & 3.94 & 3.96 & 4.06 & 4.10 & 4.12 \\
\hline $\mathrm{CD} 2$ & 3.52 & 3.93 & 3.95 & 4.05 & 4.09 & 4.11 & 4.12 \\
\hline CD3 & 3.82 & 3.96 & 4.08 & 4.10 & 4.12 & 4.13 & 4.14 \\
\hline CT1 & 3.48 & 3.62 & 3.89 & 3.94 & 3.94 & 3.95 & 3.99 \\
\hline CT2 & 3.49 & 3.63 & 3.90 & 3.92 & 3.94 & 3.95 & 4.00 \\
\hline CT3 & 3.50 & 3.63 & 3.91 & 3.92 & 3.95 & 3.96 & 4.01 \\
\hline
\end{tabular}

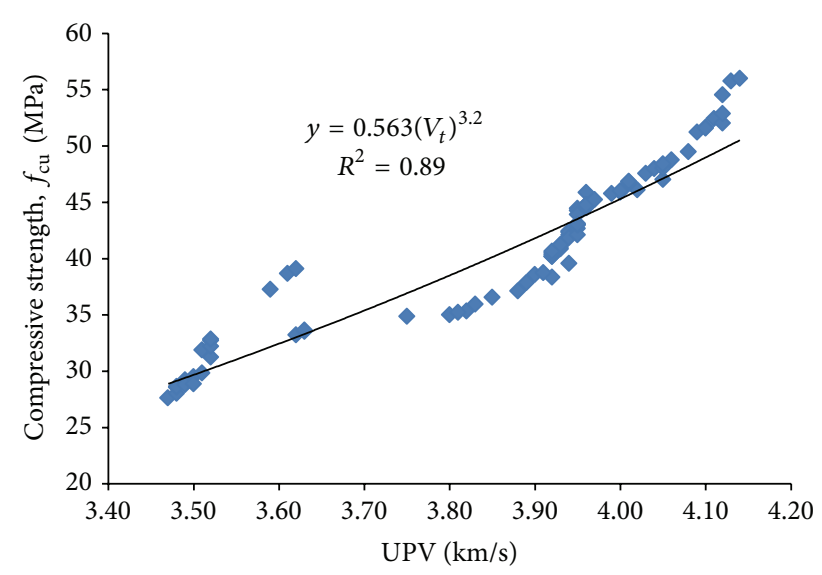

FIGURE 12: Relationship between compressive strength and ultrasonic pulse velocity.

3.6. Ultrasonic Pulse Velocity (UPV). UPV is a nondestructive method used to evaluate the quality of concrete. This method can be used to detect internal cracking and other defects, as well as changes in concrete such as deterioration due to aggressive chemical environment, freezing, and thawing. This method makes it possible to estimate the strength of concrete test specimens and in-place concrete. Based on the UPV values in Table 6, it is evident that the specimens of different OPS species and age categories have an insignificant effect on the UPV values of OPS LWHSC. However, it was found that UPV can be correlated with its corresponding compressive strength, as shown in Figure 12, with a $R^{2}$ value of 0.89 . Equation (1) is proposed to estimate the compressive strength of OPSC based on the UPV values

$$
f_{\mathrm{cu}}=0.563\left(V_{t}\right)^{3.2}
$$

where $f_{\mathrm{cu}}$ represents the cube compressive strength $(\mathrm{MPa})$ and $V_{t}$ represents the transverse ultrasonic pulse velocity $(\mathrm{km} / \mathrm{s})$.

\section{Conclusions}

The following conclusions are derived based on the results presented in this paper.

(1) A high early compressive strength was achieved for all mixes in this study, which may be due to the addition of silica fume. The addition of silica fume greatly reduces permeability and improves aggregate-cement paste interface of the concrete and consequently minimizes the induction of microcracks.

(2) The workability of concrete can be enhanced by increasing the age category of OPS aggregates. In general, all mixes achieved good and high workability.

(3) Increasing the age category of OPS aggregates slightly increases the density of the concrete. The average 28-day air-dry density and oven-dry density for the different species of OPSC is within $1970-1986 \mathrm{~kg} / \mathrm{m}^{3}$ and $1871-1890 \mathrm{~kg} / \mathrm{m}^{3}$, respectively.

(4) It is possible to produce OPS HSLWC with a 28-day compressive strength of $55 \mathrm{MPa}$ by selecting crushed dura OPS aggregates taken from oil palm trees aged between 10 and 15 years old.

(5) OPS aggregates can be used as an environmentalfriendly alternative to enhance the compressive strength of OPSLWC, provided that suitable OPS species and age category as well as size of the OPS aggregates are selected.

(6) There is a linear relationship with high correlation coefficient between the early age and 28-day compressive strength for OSPC made from aggregates of different species and age category.

(7) All OPS HSLWC are sensitive to poor curing. A period of 14 days of partial water curing is recommended for this type of LWAC. The period for partial water curing compressive strength appears to be very similar to that for continuous curing. 
(8) The water absorption value varies from 3.04 to $6.40 \%$ for all OPSC mixes, which falls within the range of good concrete.

(9) Based on the UPV test results, concrete mixes made from different OPS species and age categories can be categorized as attaining good condition after 3 days.

(10) OPS lightweight aggregates showed the possibility and acceptable performance for potential application in concrete structures. The substitution of OPS as full replacement for conventional aggregate contributes significantly to green building rating systems, a sustainable infrastructure, and mitigating of the environmental impact of the construction industry.

\section{Conflict of Interests}

The authors declare that there is no conflict of interests regarding the publication of this paper.

\section{Acknowledgment}

The authors gratefully acknowledge the financial support from University of Malaya under Institute of Research Management and Monitoring (IPPP) no. PG007-2013A and University of Malaya Research Grant (UMRG), Grant no. RP018/2012C. In addition, BCA would like to thank for the financial support of the Ministry of Higher Education Malaysia through High Impact Research Grant MOHE-HIR D000008-16001. The authors extend special thanks to Mr. Yew See Hing for collecting and providing the oil palm shell coarse aggregate species to this research.

\section{References}

[1] G. C. Hoff, "Guide for the use of low-density concrete in civil works projects," Tech. Rep. ERDC/GSL TR-02-13 (TR INP02-7), US Army Corps of Engineers, Engineer Research and Development Center, 2002.

[2] A. A. Abdullah, "Basic strength properties of lightweight concrete using agricultural wastes as aggregates," in Proceedings of the International Conference on Low-Cost Housing for Developing Countries, Roorkee, India, 1984.

[3] R. Pakiam, "Palm oil advances as Malaysia's export tax may boost shipments," http://www.bloomberg.com/news/2013-0104/palm-oil-advances-as-malaysia-s-export-tax-may-boostshipments.html.

[4] "MPOB expects $\mathrm{CPO}$ production to increase to 19 million tonnes this year," http://www.thestar.com.my/story.aspx/?file= \%2f2013\%2f1\%2f15\%2fbusiness\%2f12576771\&sec=business.

[5] "MALAYSIA: Stagnating palm oil yields impede growth," http://www.pecad.fas.usda.gov/. highlights/2012/12/Malaysia/.

[6] C. Y. May, "Malaysia: economic transformation advances oil palm industry," http://www.aocs.org/Membership/FreeCover .cfm?itemnumber $=18340$.

[7] CEBAR info sheet, "Management of agricultural waste," University of Malaya, Kuala Lumpur, Malaysia, vol. 1, no. 2, 2006.

[8] M. G. Alexander and S. Mindness, Aggregates in Concrete, Taylor and Francis Publication, Abingdon, UK, 2005.
[9] D. C. L. Teo, M. A. Mannan, V. J. Kurian, and I. Zakaria, "Flexural behaviour of reinforced lightweight OPS concrete beams," in Proceedings of the 9th International Conference on Concrete Engineering and Technology, pp. 244-252, Kuala Lumpur, Malaysia, 2006.

[10] F. O. Okafor, "Palm kernel shell as a lightweight aggregate for concrete," Cement and Concrete Research, vol. 18, no. 6, pp. 901910, 1988.

[11] P. Shafigh, M. Z. Jumaat, and H. Mahmud, "Mix design and mechanical properties of oil palm shell lightweight aggregate concrete: a review," International Journal of Physical Sciences, vol. 5, no. 14, pp. 2127-2134, 2010.

[12] E. A. Olanipekun, K. O. Olusola, and O. Ata, "A comparative study of concrete properties using coconut shell and palm kernel shell as coarse aggregates," Building and Environment, vol. 41, no. 3, pp. 297-301, 2006.

[13] U. J. Alengaram, M. Z. Jumaat, and H. Mahmud, "Ductility behaviour of reinforced palm kernel shell concrete beams," European Journal of Scientific Research, vol. 23, no. 3, pp. 406420, 2008.

[14] M. Z. Jumaat, U. Johnson Alengaram, and H. Mahmud, "Shear strength of oil palm shell foamed concrete beams," Materials and Design, vol. 30, no. 6, pp. 2227-2236, 2009.

[15] U. J. Alengaram, H. Mahmud, and M. Z. Jumaat, "Comparison of mechanical and bond properties of oil palm kernel shell concrete with normal weight concrete," International Journal of Physical Sciences, vol. 5, no. 8, pp. 1231-1239, 2010.

[16] D. C. L. Teo, M. A. Mannan, and J. V. Kurian, "Flexural behaviour of reinforced lightweight concrete beams made with oil palm shell (OPS)," Journal of Advanced Concrete Technology, vol. 4, no. 3, pp. 459-468, 2006.

[17] P. Shafigh, M. Z. Jumaat, and H. Mahmud, "Oil palm shell as a lightweight aggregate for production high strength lightweight concrete," Construction and Building Materials, vol. 25, no. 4, pp. 1848-1853, 2011.

[18] P. Shafigh, M. Z. Jumaat, H. B. Mahmud, and U. J. Alengaram, "A new method of producing high strength oil palm shell lightweight concrete," Materials and Design, vol. 32, no. 10, pp. 4839-4843, 2011.

[19] M. K. Yew, H. Mahmud, B. C. Ang, and M. C. Yew, "Effects of heat treatment on oil palm shell coarse aggregates for high strength lightweight concrete," Materials \& Design, vol. 54, pp. 702-707, 2014.

[20] M. A. Mannan, J. Alexander, C. Ganapathy, and D. C. L. Teo, "Quality improvement of oil palm shell (OPS) as coarse aggregate in lightweight concrete," Building and Environment, vol. 41, no. 9, pp. 1239-1242, 2006.

[21] ASTM C192-90a, "Standard test method of making and curing concrete test specimens in the laboratory," Annual Book of ASTM Standards, 1990.

[22] M. A. Mannan and C. Ganapathy, "Engineering properties of concrete with oil palm shell as coarse aggregate," Construction and Building Materials, vol. 16, no. 1, pp. 29-34, 2002.

[23] J. Newman and P. Owens, Properties of Lightweight Concrete, Advanced Concrete Technology Set, Butterworth-Heinemann, Oxford, UK, 2003.

[24] H. A. Razak, H. K. Chai, and H. S. Wong, "Near surface characteristics of concrete containing supplementary cementing materials," Cement and Concrete Composites, vol. 26, no. 7, pp. 883-889, 2004. 
[25] D. C. L. Teo, M. A. Mannan, V. J. Kurian, and C. Ganapathy, "Lightweight concrete made from oil palm shell (OPS): structural bond and durability properties," Building and Environment, vol. 42, no. 7, pp. 2614-2621, 2007.

[26] M. S. Shetty, Concrete Technology: Theory and Practice, First Multicolour Illustrative Revised Edition, S. Chand, New Delhi, India, 2005.

[27] U. J. Alengaram, H. Mahmud, and M. Z. Jumaat, "Enhancement and prediction of modulus of elasticity of palm kernel shell concrete," Materials and Design, vol. 32, no. 4, pp. 2143-2148, 2011.

[28] ACI Committee 308, "Proposed ACI standard: standard practice for curing concrete," ACI Concrete International, vol. 2, no. 11, pp. 45-55, 1980.

[29] P. K. Mehta and P. J. M. Monteiro, Concrete: Microstructure, Properties, and Materials, McGraw-Hill, New York, NY, USA, 3rd edition, 2006.

[30] A. M. Neville, Properties of Concrete, (CTP-VVP), Kuala Lumpur, Malaysia, 14th edition, 2008.

[31] K. G. Babu and D. S. Babu, "Behaviour of lightweight expanded polystyrene concrete containing silica fume," Cement and Concrete Research, vol. 33, no. 5, pp. 755-762, 2003.

[32] L. Gündüz and I. Uğur, "The effects of different fine and coarse pumice aggregate/cement ratios on the structural concrete properties without using any admixtures," Cement and Concrete Research, vol. 35, no. 9, pp. 1859-1864, 2005. 

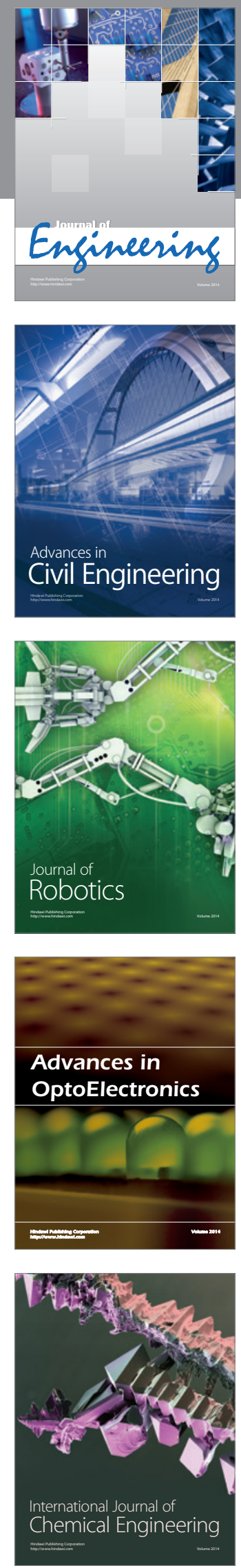

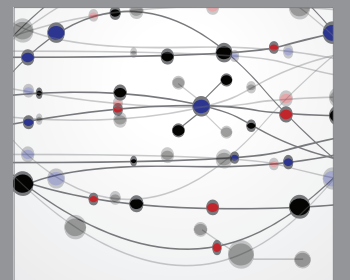

The Scientific World Journal
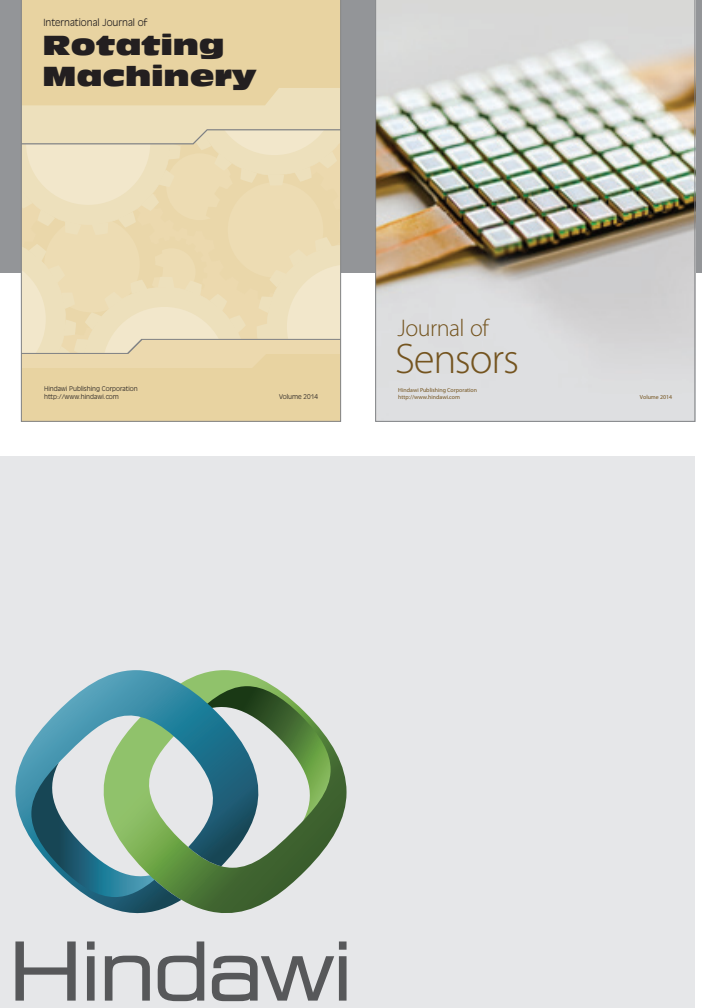

Submit your manuscripts at http://www.hindawi.com
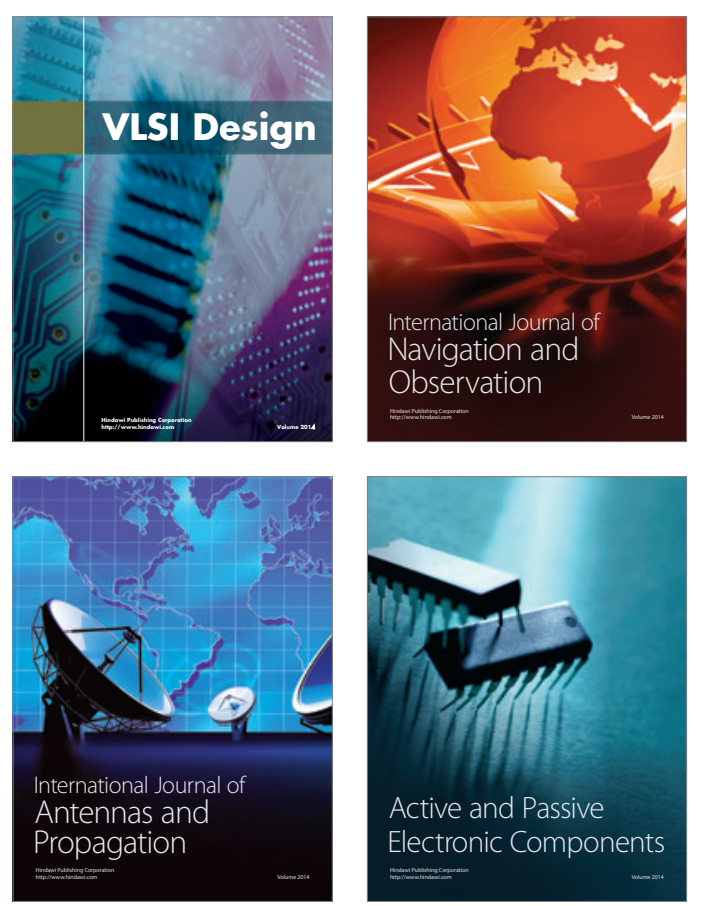
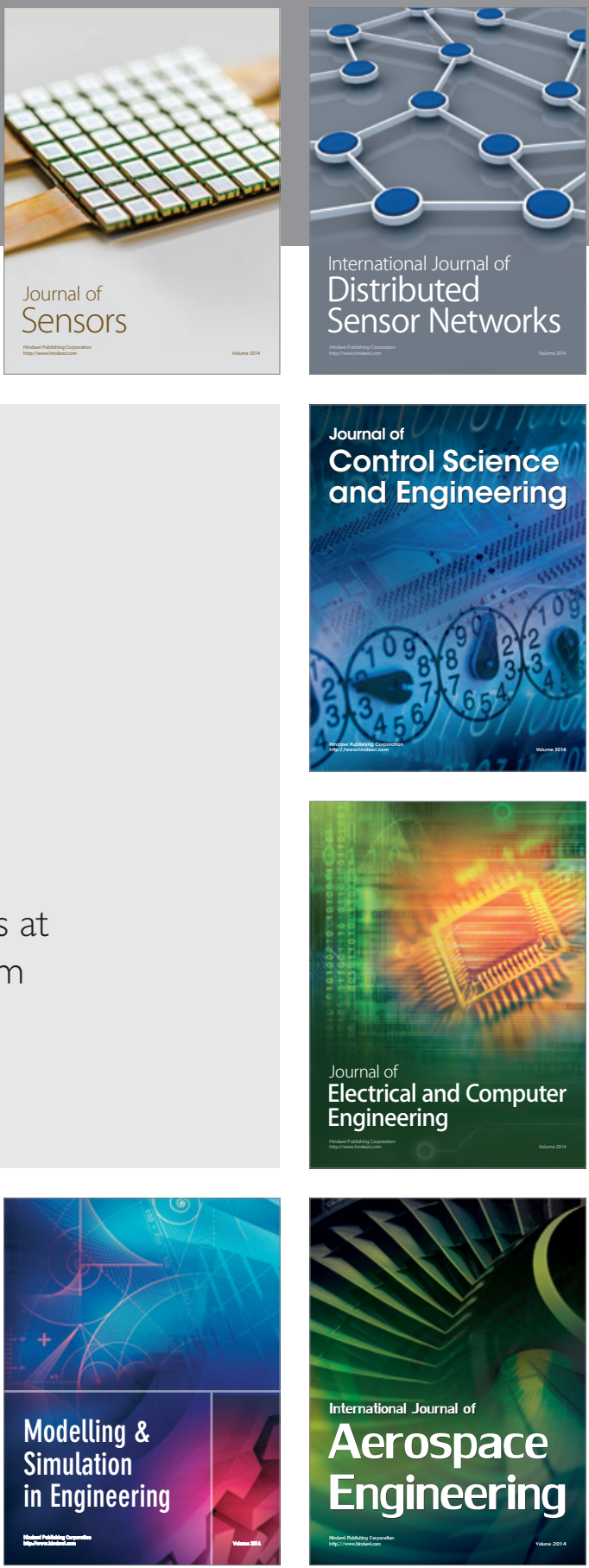

Journal of

Control Science

and Engineering
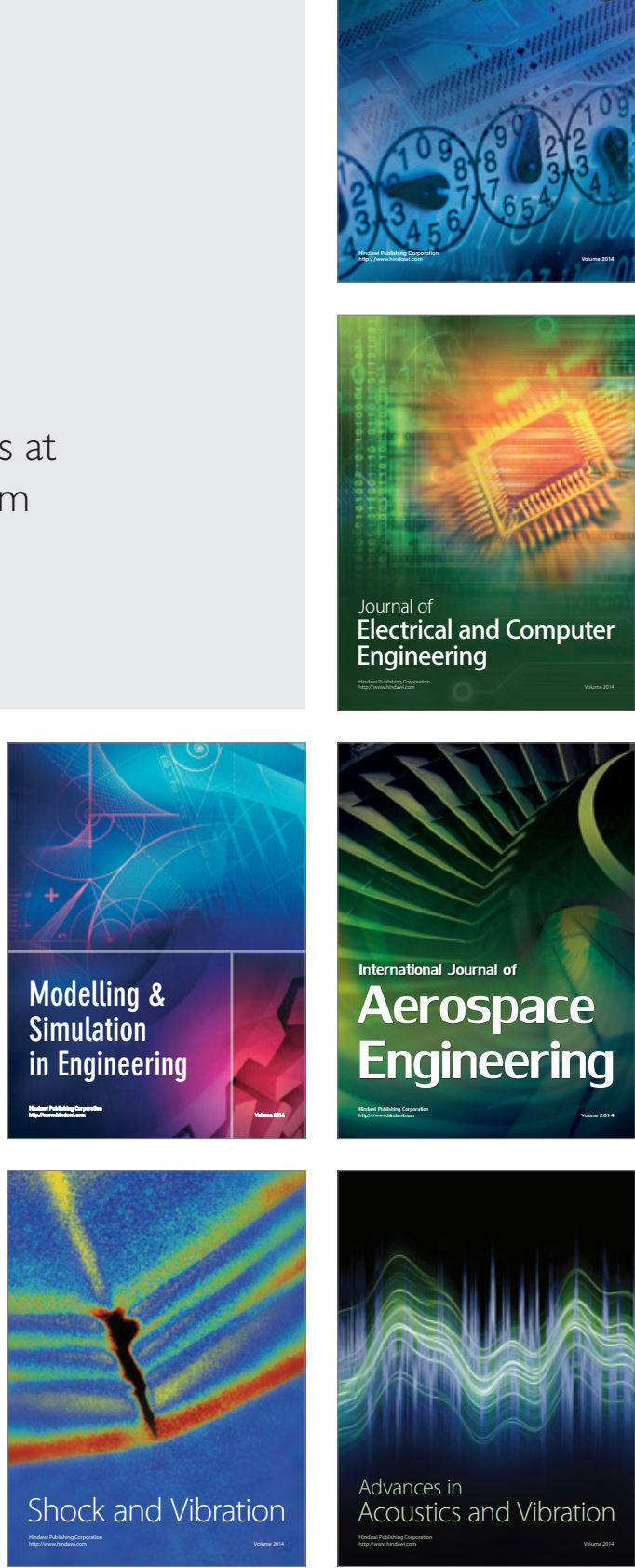